\title{
Long-term sucrose-drinking causes increased body weight and glucose intolerance in normal male rats
}

\author{
Takahiro Kawasaki*, Akiko Kashiwabara, Tadashi Sakai, Kanji Igarashi, Nobuyuki Ogata, Hiroyuki Watanabe, \\ Kaoru Ichiyanagi and Toshikazu Yamanouchi \\ Department of Internal Medicine, Teikyo University School of Medicine, 2-11-1 Kaga, Itabashi, Tokyo, 173-8605, Japan
}

(Received 24 May 2004 - Revised 6 January 2005 - Accepted 10 January 2005)

\begin{abstract}
The current epidemic of diabetes likely reflects marked changes in environmental factors, although genetic susceptibility plays a powerful role in the occurrence of diabetes in certain populations. We investigated whether long-term sucrose-drinking causes hyperglycaemia in male Wistar-Imamichi littermates $(n$ 32 ), which are not genetically susceptible to diabetes or obesity. Each litter was divided equivalently into two groups, the sucrose group and the control group. The sucrose group received $300 \mathrm{~g} / \mathrm{l}$ sucrose water and the control group received regular water until 42 weeks of age. Rats were weighed every 1 or 2 weeks. Oral glucose tolerance tests were performed at 28 and 36 weeks of age. Plasma glucose and insulin concentrations were measured. Body weights were significantly greater in the sucrose group than in the control group in 18 -week-old rats $(P<0 \cdot 05)$, and the difference between the two groups reached $163 \mathrm{~g}$ by the end of the study $(P<0 \cdot 01)$. The $120 \mathrm{~min}$ post-load plasma glucose concentration in the sucrose group was 11.4 (SD 2.8 ) $\mathrm{mmol} / \mathrm{l}$ in 28 -week-old rats and $12.7(\mathrm{SD} 2 \cdot 2) \mathrm{mmol} / \mathrm{l}$ in 36-week-old rats, while that of the control group remained approximately $7 \cdot 3-7 \cdot 7 \mathrm{mmol} / \mathrm{l}$. In the sucrose group, the plasma insulin peak occurred $30 \mathrm{~min}$ post-load at 28 weeks of age; but the peak disappeared and hyperinsulinaemia was prolonged at 36 weeks of age. In conclusion, long-term sucrose-drinking causes increased body weight and glucose intolerance in normal male rats.
\end{abstract}

Dietary sucrose: Experimental diabetes mellitus: Type 2 diabetes mellitus: Environmental: Litter size: Wistar rats

The increased prevalence of diabetes in the USA has continued unabated through the late 1990s to the present day (Mokdad et al. 2001). The prevalence of diabetes in Japan and other developed countries is also believed to be increasing. Although genetic susceptibility plays a powerful role in the occurrence of diabetes in certain populations, population gene pools shift quite slowly. Therefore, the current epidemic likely reflects marked changes in environmental factors, especially lifestyle. Lifestyle changes, characterized by decreased physical activity and increased energy consumption, have promoted obesity, which is a remarkably strong risk factor for diabetes (Edelstein et al. 1997). A striking increase in the prevalence of obesity in the USA has been reported (Kuczmarski et al. 1994). Other developed countries are most likely experiencing a similar increase in obesity prevalence. In regard to dietary components, fat intake appears to be an important determinant of diabetes risk, independent of total caloric intake (Tsunehara et al. 1990; Marshall et al. 1997). On the other hand, metabolic studies of the risks and benefits of sugar ingestion have been controversial. Janket et al. (2003) reported that sugar intake does not play a deleterious role in primary prevention of type 2 diabetes. However, a recent prospective study from Ludwig et al. (2001) showed a clear-cut, grade relation between the consumption of sugar-sweetened drinks and the development of obesity in children. Moreover, James et al. (2004) reported that a school-based education programme produced a modest reduction in the number of carbonated drinks consumed, which was associated with a reduction in the number of overweight and obese children. In the present study, we investigated whether environmental factors cause hyperglycaemia in an ordinary strain of rats that is not genetically susceptible to diabetes or obesity. We studied littermates divided equally into two groups, as we considered them genetically closer. One group received $300 \mathrm{~g} / \mathrm{l}$ sucrose water and the other group received regular water until 42 weeks of age. We compared glucose tolerance and body weight between the two groups.

\section{Experimental methods}

Experimental animals

Wistar-Imamichi rats, which were established by Dr Tomonori Imamichi in 1960, are the offspring of Wistar standard strain lot no. 1859 , of which three breeding pairs were brought to Japan in 1938. Wistar-Imamichi rats are an ordinary experimental strain used in Japan. They do not develop obesity and diabetes under normal conditions. All procedures were in accordance with the Guide for the Care and Use of Laboratory Animals of the National Institutes of Health. Six breeding pairs of Wistar-Imamichi rats were purchased from the Institute for Animal Reproduction (Ibaragi, Japan). The rats were bred in the laboratory animal unit of our university and produced thirty-two male offspring. The litters remained with their parents until 3 weeks of age. After matching 
the body weights in each of the litters, each litter was divided equally into two groups, a sucrose group and a control group. The rats were housed individually in an environmentally controlled room with a $12 \mathrm{~h}$ light-dark cycle (light from 7.00 to 19.00 hours). Rats had free access to food and a designated type of water (sucrose water or regular water). Rats in the sucrose group ( $n$ 16) received $300 \mathrm{~g} / \mathrm{l}$ sucrose water and rats in the control group $(n 16)$ received regular water from 3 to 42 weeks of age. All animals received the same basal non-purified diet (MF, Oriental Yeast Co. Ltd, Tokyo, Japan) (Table 1).

\section{Measurement of body weight}

Rats were weighed every week from 3 to 16 weeks of age and every 2 weeks from 16 to 42 weeks of age. Weight was measured by an A \& D electronic balance (A \& D Co. Ltd, Tokyo, Japan) at 9.00 hours.

\section{Fasting blood samples and intravenous and oral glucose tolerance tests}

Intravenous glucose tolerance tests (IVGTTs) were performed on all rats at 8 and 16 weeks of age. Oral glucose tolerance tests (OGTTs) were performed on all rats at 28 and 36 weeks of age. Fasting blood samples only were obtained from each rat at 12 and 24 weeks of age. Food was removed and $300 \mathrm{~g} / \mathrm{l}$ sucrose water was changed to regular water at 18.00 hours $1 \mathrm{~d}$ before the tests. At 9.00 hours a fasting blood sample $(1000 \mu \mathrm{l})$ was taken from a peripheral subcutaneous vein of the neck. Rat hairs had been shaved and skin had been revealed on the region at $1 \mathrm{~d}$ before the blood collections. We were able to detect a peripheral subcutaneous vein of the region and punctured it with a fine needle (external diameter $0.45 \mathrm{~mm}$, length $13.0 \mathrm{~mm}$ ) fitted with a $1.0 \mathrm{ml}$ volume syringe. Then, glucose $(1 \mathrm{~g} / \mathrm{kg}$ ) was administered using a $500 \mathrm{~g} / \mathrm{l}$ glucose solution (Otsuka, Tokushima, Japan) that was loaded via a peripheral subcutaneous vein of the inguinal region or oral catheter. Rat hairs had been shaved and skin had been revealed on the region at $1 \mathrm{~d}$ before the IVGTTs. We were able to detect a peripheral subcutaneous vein of the region and punctured it with a fine needle (external diameter $0.45 \mathrm{~mm}$, length $13.0 \mathrm{~mm}$ ) fitted with a $2.5 \mathrm{ml}$ volume syringe which was filled with a $500 \mathrm{~g} / \mathrm{l}$ glucose solution. Blood samples were taken alternately from the peripheral subcutaneous veins on each side of

Table 1. Composition of the commercial diet*

\begin{tabular}{ll}
\hline Component & Amount $(\mathrm{g} / 100 \mathrm{~g}$ diet $)$ \\
\hline Water & $7 \cdot 0$ \\
Protein & $24 \cdot 0$ \\
Lipid & $5 \cdot 1$ \\
Fibre & $2 \cdot 7$ \\
Ash & $3 \cdot 2$ \\
Nitrogen-free extracts & $54 \cdot 5$ \\
Mineral mixture $\dagger$ & $3 \cdot 2$ \\
Vitamin and amino acid mixtureł & 0.18
\end{tabular}

MF, Oriental Yeast, Tokyo, Japan.

†The mineral mixture provided ( $\mathrm{g} / \mathrm{kg}$ diet): calcium, 11.0; phosphorus, 8.3; magnesium, 2.5; sodium, 2.6; potassium, 7.5; iron, 0.16; zinc, 0.49; copper, 0.074; manganese, 0.49 .

$\ddagger$ The vitamin and amino acid mixture provided (per $\mathrm{kg}$ diet): retinol, $315 \mathrm{mg}$; cholecalciferol, $308 \mu \mathrm{g}$; $\alpha$-tocopherol, $63 \mathrm{mg}$; menadione, $0.4 \mathrm{mg}$; thiamine, $19 \mathrm{mg}$; riboflavin, $13 \mathrm{mg}$; pyridoxine $\mathrm{HCl}, 8 \mathrm{mg}$; niacin, $40 \mathrm{mg}$; pantothenic acid, $19 \mathrm{mg}$; biotin, $0.2 \mathrm{mg}$; inositol, $600 \mathrm{mg}$; choline, $1 \mathrm{~g}$; folic acid, $0.4 \mathrm{mg}$; ascorbic acid, $54 \mathrm{mg}$. the neck at $30 \mathrm{~min}(200 \mu \mathrm{l})$ and $120 \mathrm{~min}(1000 \mu \mathrm{l})$ after loading for the IVGTT in 8-week-old rats. Serial blood samples $(1000 \mu \mathrm{l})$ were taken alternately from the peripheral subcutaneous veins on each side of the neck at 30,60 and $120 \mathrm{~min}$ after loading for the IVGTT in 16-week-old rats, as well as for the OGTTs in 28- and 36 -week-old rats. All procedures were performed without anaesthesia by an investigator who was experienced in the handling of rats. The rats were restrained for a short amount of time during oral catheterization and blood collection. Pre-implanted cannulae were not used in the present study.

\section{Measurements of plasma glucose and insulin concentrations}

After blood samples were obtained, part of the sample was used to immediately measure plasma glucose (PG) by Novo Assist Plus (Novo Nordisk, Denmark). Each sample was measured twice. The remaining part of the blood sample was immediately centrifuged. The plasma was obtained and stored at $-40^{\circ} \mathrm{C}$ until assayed. Plasma insulin concentrations, which were measured by Mercodia Rat Insulin ELISA systems (Mercodia, Uppsala, Sweden), were examined at fasting and $120 \mathrm{~min}$ after loading for the IVGTT in 8-week-old rats and at fasting, $30 \mathrm{~min}, 60 \mathrm{~min}$ and $120 \mathrm{~min}$ after loading for the IVGTT in 16-week-old rats and the OGTTs in 28- and 36-week-old rats. Plasma insulin concentrations were measured in six representative rats per group. Each sample was measured in duplicate.

\section{Statistical analyses}

Data are presented as means and their standard deviations. For normally distributed data, statistical analysis was performed with a Student's paired or unpaired $t$ test. For any difference in distribution between groups, Wilcoxon's signed-rank test or Welch's unpaired $t$ test was performed. All analyses were done with Stat View software package version 4.5 (Abacus Concepts, Berkeley, CA, USA). $P$ values $<0.05$ were considered statistically significant.

\section{Results}

Comparison of body weights between the control and sucrose groups

As shown in Fig. 1 and Table 2, rat body weights were significantly greater in the control group $(n 16)$ than in the sucrose group ( $n$ 16) during the younger period between 4 and 9 weeks of age (the small inserted graph). Then, rat body weights were significantly greater in the sucrose group than in the control group at 18 weeks of age (control group, 486 (SD 44) g; sucrose group, 517 (SD $45 \mathrm{~g}$ ); $P<0.05$ ). The difference in body weights between the two groups increased as the rats grew. At the end of the study, the difference in mean body weights between the two groups was $163 \mathrm{~g}$ (control group, 636 (SD 74) g; sucrose group, 799 (SD 100) g; $P<0.01$ ), i.e. the sucrose group became $25.6 \%$ heavier than the control group.

\section{Serial changes in fasting plasma glucose and insulin concentrations}

Fasting plasma insulin concentrations in the sucrose group and the control group were equivalent at 8 weeks of age. Then, the fasting 


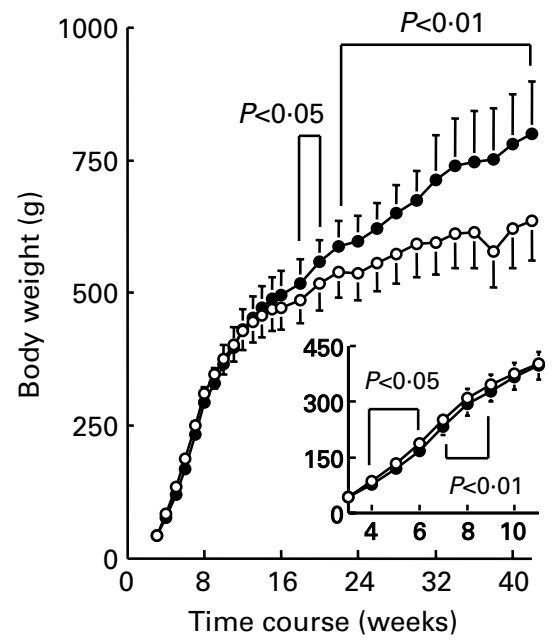

Fig. 1. Comparison of body weight between the control group and the sucrose group. As shown in the small inserted graph, rat body weights were significantly greater in the control group $(O, n 16)$ than in the sucrose group $(\bullet, n 16)$ during the younger period between 4 and 9 weeks of age. Then, rat body weights were significantly greater in the sucrose group than in the control group at 18 weeks of age $(P<0.05)$. The difference in body weights between the two groups increased as the rats grew. Values are means with their standard deviations depicted by vertical bars.

plasma insulin concentration in the sucrose group increased to six-fold that in the control group at 12 weeks of age $(P<0 \cdot 01)$, although no difference in body weights was observed between the two groups (Table 2). After 12 weeks of age, the fasting plasma insulin concentration in the sucrose group remained at least three times higher than that in the control group. Fasting plasma glucose (FPG) concentrations in the sucrose group were significantly higher than those in the control group at 28 $(P<0.01)$ and $36(P<0.05)$ weeks of age. No significant difference in FPG was observed at 8,12 and 24 weeks of age.

\section{Intravenous glucose tolerance tests at 8 weeks of age}

PG concentrations in the sucrose group ( $n$ 16) were significantly $(P<0.05)$ higher than those in the control group $(n 16)$ at $30 \mathrm{~min}$ (control group, 11.2 (SD 2.5) mmol/l; sucrose group, 14.3 (SD 2.1) $\mathrm{mmol} / \mathrm{l}$ ) and $60 \mathrm{~min}$ (control group, $9.2(\mathrm{SD} 2 \cdot 1) \mathrm{mmol} / \mathrm{l}$; sucrose group, $12.3(\mathrm{SD} 2 \cdot 1) \mathrm{mmol} / \mathrm{l}$ ) after loading (Fig. 2), although no significant difference between the two groups was observed in FPG (Table 2). No significant difference between the two groups was observed in plasma insulin concentrations at fasting and $120 \mathrm{~min}$ after loading (control group $(n$ 6), 0.31 (SD 0.23) $\mu \mathrm{g} / \mathrm{l}$; sucrose group ( $n$ 6), 0.46 (SD 0.31) $\mu \mathrm{g} / \mathrm{l}$ ).

\section{Intravenous glucose tolerance tests at 16 weeks of age}

PG concentrations in the sucrose group ( $n$ 16) were significantly higher than those in the control group $(n 16)$ at $30 \mathrm{~min}$ (control group, 10.8 (SD 2.5) $\mathrm{mmol} / \mathrm{l}$; sucrose group, 14.5 (SD 2.1) $\mathrm{mmol} / \mathrm{l}$ ), $60 \mathrm{~min}$ (control group, 8.9 (sD 1.3) $\mathrm{mmol} / \mathrm{l}$; sucrose group, $12.5(\mathrm{SD} 2.7) \mathrm{mmol} / \mathrm{l}$ ) and $120 \mathrm{~min}$ (control group, 6.7 (SD 1.0) $\mathrm{mmol} / \mathrm{l}$; sucrose group, 8.3 (SD 2.1$) \mathrm{mmol} / \mathrm{l}$ ) after loading $(P<0.01$; Fig. 3(A)), while FPG levels were significantly lower in the sucrose group than in the control group $(P<0.05$; Table 2). Plasma insulin concentrations in the sucrose group $(n 6)$ were significantly higher than those in the control group $(n 6)$ at all timepoints (control group, 0.95 (SD 0.56) $\mu \mathrm{g} / \mathrm{l}$ at $30 \mathrm{~min}, 1.05$ (SD $0.70) \mu \mathrm{g} / \mathrm{l}$ at $60 \mathrm{~min}, 0.86(\mathrm{SD} 0.52) \mu \mathrm{g} / \mathrm{l}$ at $120 \mathrm{~min}$; sucrose group, $3.53(\mathrm{SD} 0.51) \mu \mathrm{g} / \mathrm{l}$ at $30 \mathrm{~min}, 3.64$ (SD 0.74) $\mu \mathrm{g} / \mathrm{l}$ at $60 \mathrm{~min}, 2.94$ (SD 0.91) $\mu \mathrm{g} / \mathrm{l}$ at $120 \mathrm{~min} ; P<0 \cdot 01$; Fig. 3(B)).

\section{Oral glucose tolerance tests at 28 weeks of age}

PG concentrations in the sucrose group were significantly higher than those in the control group at all time-points (control group, $8.1(\mathrm{SD} 1.5) \mathrm{mmol} / \mathrm{l}$ at $30 \mathrm{~min}, 10.0(\mathrm{SD} 2.5) \mathrm{mmol} / \mathrm{l}$ at $60 \mathrm{~min}$; sucrose group, $11.0(\mathrm{SD} 1.3) \mathrm{mmol} / \mathrm{l}$ at $30 \mathrm{~min}, 13.6$ (SD 1.9) $\mathrm{mmol} / \mathrm{l}$ at $60 \mathrm{~min} ; P<0.01$; Fig. $4(\mathrm{~A}))$. PG concentrations remained $11.4(\mathrm{SD} 2.8) \mathrm{mmol} / \mathrm{l}$ at $120 \mathrm{~min}$ after loading in the sucrose group, while they remained 7.3 (SD 0.9 ) $\mathrm{mmol} / \mathrm{l}$ in the control group. Plasma insulin concentrations in the sucrose group were significantly greater than those in the control group at fasting $(P<0.01), 30 \mathrm{~min}$ (control group, $1.13(\mathrm{SD} 0.55) \mu \mathrm{g} / \mathrm{l}$; sucrose group, 3.42 (SD 0.55) $\mu \mathrm{g} / 1 ; P<0.01$ ), $60 \mathrm{~min}$ (control group, 1.45 (SD 0.36) $\mu \mathrm{g} / \mathrm{l}$; sucrose group, 2.85 (SD 0.82) $\mu \mathrm{g} / \mathrm{l}$; $P<0.05$ ) and $120 \mathrm{~min}$ (control group, 1.08 (SD 0.31 ) $\mu \mathrm{g} / \mathrm{l}$; sucrose group, 2.85 (SD 0.74) $\mu \mathrm{g} / 1 ; P<0.01$ ) after loading. In the sucrose group, the peak in plasma insulin concentrations occurred $30 \mathrm{~min}$ after loading (Fig. 4(B)).

Table 2. Serial changes of fasting plasma glucose (FPG) and insulin over 36 weeks followed in control and sucrose-loading groups.

\begin{tabular}{|c|c|c|c|c|c|c|c|c|c|c|c|c|}
\hline & \multicolumn{12}{|c|}{ Weeks } \\
\hline & \multicolumn{2}{|c|}{8} & \multicolumn{2}{|c|}{12} & \multicolumn{2}{|c|}{16} & \multicolumn{2}{|c|}{24} & \multicolumn{2}{|c|}{28} & \multicolumn{2}{|c|}{36} \\
\hline & Mean & SD & Mean & SD & Mean & SD & Mean & SD & Mean & SD & Mean & SD \\
\hline \multicolumn{13}{|l|}{ Control $(n 16)$} \\
\hline FPG $(\mathrm{mmol} / \mathrm{l})$ & 4.45 & 0.43 & 4.48 & 0.38 & $4 \cdot 87$ & 0.59 & 4.91 & 0.71 & $5 \cdot 21$ & 0.58 & 5.00 & 0.48 \\
\hline Insulin $(\mu \mathrm{g} / \mathrm{l}) \ddagger$ & 0.12 & 0.08 & 0.13 & 0.09 & 0.62 & 0.49 & 0.57 & 0.35 & 0.64 & 0.35 & 0.56 & 0.31 \\
\hline Weight (g) & 310 & 23 & 428 & 35 & 471 & 40 & 537 & 50 & 573 & 56 & 614 & 67 \\
\hline \multicolumn{13}{|c|}{ Sucrose loading ( $n$ 16) } \\
\hline FPG $(\mathrm{mmol} / \mathrm{l})$ & 4.43 & 0.58 & 4.54 & 0.57 & 4.49 & $0.48 \dagger$ & $5 \cdot 24$ & 0.98 & $5 \cdot 88$ & $0.61^{*}$ & $5 \cdot 61$ & $0.27 \dagger$ \\
\hline Insulin $(\mu \mathrm{g} / \mathrm{l}) \ddagger$ & 0.13 & 0.10 & 0.82 & $0.48^{\star}$ & 1.84 & $0.58^{\star}$ & 2.08 & $1 \cdot 01^{*}$ & 1.90 & $0.82^{*}$ & $2 \cdot 78$ & $1.73 \dagger$ \\
\hline Weight (g) & 293 & $30 \dagger$ & 430 & 39 & 497 & 45 & 597 & $49^{\star}$ & 650 & $53^{\star}$ & 748 & $94^{*}$ \\
\hline
\end{tabular}

${ }^{\star} P<0.01$

$\dagger P<0.05$ mean values were significantly different from the control group:

¥Insulin measured in six representative cases in both groups. 


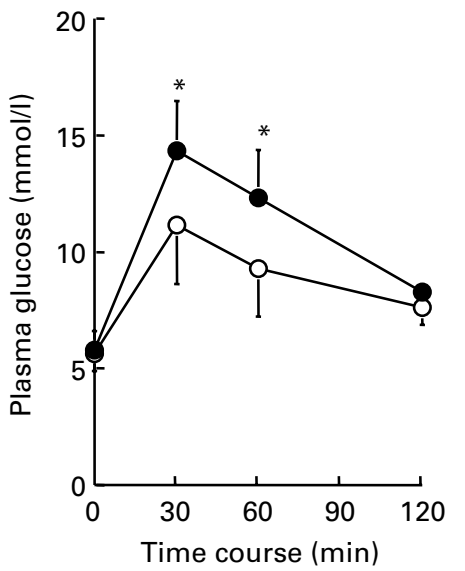

Fig. 2. Intravenous glucose tolerance test at 8 weeks of age. Glucose $(1 \mathrm{~g} / \mathrm{kg})$ was loaded via a peripheral subcutaneous vein of the inguinal region. Plasma glucose concentrations in the sucrose group $(\bullet, n$ 16) were significantly $\left({ }^{*} P<0.05\right)$ higher than those in the control group $(O, n 16)$ at 30 and $60 \mathrm{~min}$ after loading, although there was no significant difference in fasting plasma glucose between the two groups. Values are means with their standard deviations depicted by vertical bars.

\section{Oral glucose tolerance tests at 36 weeks of age}

PG concentrations in the sucrose group were significantly higher than those in the control group at fasting $(P<0.05), 30 \mathrm{~min}$ (control group, $10 \cdot 1$ (SD 3.3) $\mathrm{mmol} / \mathrm{l}$; sucrose group, $14 \cdot 7$ (SD 2.2) $\mathrm{mmol} / \mathrm{l}$; $P<0.01$ ), $60 \mathrm{~min}$ (control group, 10.4 (SD 3.6) $\mathrm{mmol} / \mathrm{l}$; sucrose group, 15.2 (SD 2.2) $\mathrm{mmol} / \mathrm{l} ; P<0.05$ ) and $120 \mathrm{~min}$ (control group, $7 \cdot 7$ (SD 2.2) mmol/l; sucrose group, 12.7 (SD 2.2) $\mathrm{mmol} / \mathrm{l}$; $P<0.01$ ) after loading (Fig. 5(A)). PG concentrations at $120 \mathrm{~min}$ after loading in the sucrose group were higher than at 28 weeks of age, while they remained at approximately $7.7 \mathrm{mmol} / \mathrm{l}$ in the control group. Plasma insulin concentrations in the sucrose group were significantly higher than those in the control group at fasting $(P<0.05)$, 30 min (control group, 1.27 (SD 0.41) $\mu \mathrm{g} / \mathrm{l}$; sucrose group, 3.93 (SD $1.95) \mu \mathrm{g} / \mathrm{l} ; P<0.05$ ), $60 \mathrm{~min}$ (control group, 1.50 (SD 0.25 ) $\mu \mathrm{g} / \mathrm{l}$; sucrose group, 4.49 (SD 1.42) $\mu \mathrm{g} / \mathrm{l} ; P<0.01$ ) and $120 \mathrm{~min}$ (control group, 1.16 (SD 0.12) $\mu \mathrm{g} / \mathrm{l}$; sucrose group, 4.29 (SD 1.02) $\mu \mathrm{g} / \mathrm{l}$;
(A)

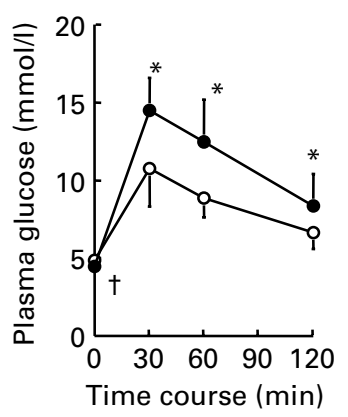

(B)

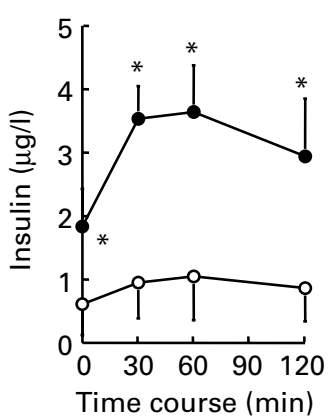

Fig. 3. Intravenous glucose tolerance test at 16 weeks of age. Glucose $(1 \mathrm{~g} / \mathrm{kg})$ was loaded via a peripheral subcutaneous vein of the inguinal region. (A), Plasma glucose concentrations in the sucrose group $(\bullet, n$ 16) were significantly $\left({ }^{\star} P<0.01\right)$ higher than those in the control group $(O, n 16)$ at 30,60 and $120 \mathrm{~min}$. Fasting plasma glucose concentrations were significantly lower in the sucrose group than in the control group $(\dagger P<0.05)$. (B), Plasma insulin concentrations in the sucrose group $(\bullet, n 6)$ were significantly higher than those in the control group $(O, n 6)$ at all time-points $\left({ }^{\star} P<0.01\right)$. Values are means with their standard deviations depicted by vertical bars.
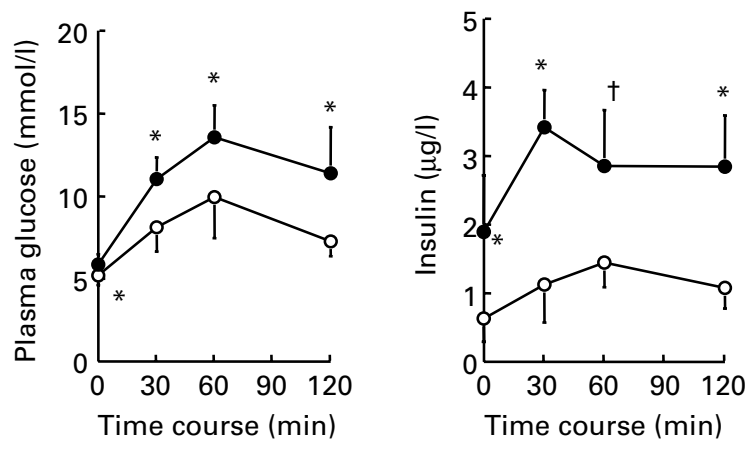

Fig. 4. Oral glucose tolerance test at 28 weeks of age. Glucose $(1 \mathrm{~g} / \mathrm{kg})$ was loaded via oral catheter. (A), Plasma glucose concentrations in the sucrose group $(\bullet, n 16)$ were significantly higher than those in the control group $(\mathrm{O}, n 16)$ at all time-points $\left({ }^{\star} P<0 \cdot 01\right)$. (B), Plasma insulin concentrations in the sucrose group $(\bullet, n 6)$ were significantly greater than those in the control group $(O, n 6)$ at fasting $\left({ }^{\star} P<0.01\right), 30 \mathrm{~min}\left({ }^{\star} P<0.01\right), 60 \mathrm{~min}(\dagger P<0.05)$ and $120 \mathrm{~min}\left({ }^{*} P<0.01\right)$ after loading. Values are means with their standard deviations depicted by vertical bars.

$P<0.01)$ after loading. In the sucrose group, the plasma insulin peak at $30 \mathrm{~min}$ after loading that was observed at 28 weeks of age had disappeared and hyperinsulinaemia was prolonged (Fig. 5(B)).

\section{Discussion}

The present study demonstrated that long-term sucrose-drinking causes increased body weight and glucose intolerance in an ordinary strain of rats that is not genetically susceptible to diabetes or obesity. Several aspects of our study design are unique and advantageous. First, our experimental period was longer than 10 months. The longer examination period enabled significant differences in body weights and glucose tolerance to develop between the two groups. Four previous studies had the same experimental period as the present study (Blakely et al. 1981; Tulp et al. 1991; Levi \& Werman 1998; Chicco et al. 2003). However, only one study could demonstrate a significant weight gain in an ordinary strain of rats that was fed a sucrose-rich diet (Chicco et al. 2003). The second unique aspect of our study was the use of glucose tolerance tests.
(A)

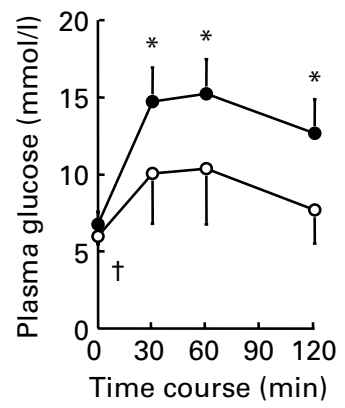

(B)

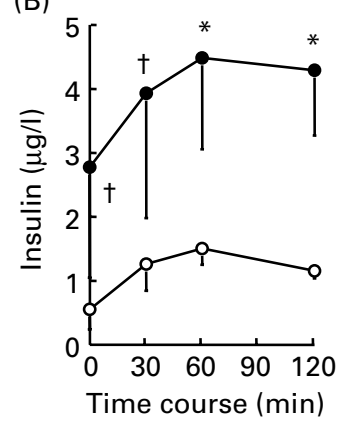

Fig. 5. Oral glucose tolerance test at 36 weeks of age. Glucose $(1 \mathrm{~g} / \mathrm{kg})$ was loaded via oral catheter. (A), Plasma glucose concentrations in the sucrose group $(\bullet, n 16)$ were significantly higher than those in the control group $\left(O, n\right.$ 16) at fasting $(\dagger P<0.05), 30 \mathrm{~min}\left({ }^{\star} P<0.01\right), 60 \mathrm{~min}\left({ }^{\star} P<0.01\right)$ and $120 \mathrm{~min}\left({ }^{\star} P<0.01\right)$ after loading. (B), Plasma insulin concentrations in the sucrose group $(\bullet, n 6)$ were significantly higher than those in the control group $(O, n 6)$ at fasting $(\dagger P<0.05), 30 \mathrm{~min}(\dagger P<0.05), 60 \mathrm{~min}\left({ }^{*} P<0.01\right)$ and $120 \mathrm{~min}\left({ }^{*} P<0.01\right)$ after loading. Values are means with their standard deviations depicted by vertical bars. 
This allowed us to demonstrate that the mean 120 min post-load blood glucose concentration in the sucrose group was $>11.1 \mathrm{mmol} / \mathrm{l}$ in 28 -week-old rats and then reached approximately $12.5 \mathrm{mmol} / \mathrm{l}$ in 36 -week-old rats. Oral glucose tolerance tests were performed in some previous studies (Blakely et al. 1981; Koyama et al. 1988; Stark et al. 2000). However, only one study could demonstrate the significantly higher mean 120 min post-load blood glucose concentration in fructose- or sucrose-loaded rats. Blakely et al. (1981) examined the oral glucose load (250 mg per $100 \mathrm{~g}$ body weight) at 3, 5, 7, 9 and 15 months in fructose-loaded rats. Although the serum glucose concentrations of the fructose-loaded rats were significantly higher than those of the control rats at some time-points, the mean 120 min post-load blood glucose concentrations in the fructose-loaded rats failed to reach $11.1 \mathrm{mmol} / \mathrm{l}$. The third unique aspect of our study was that we used littermates so that the comparable groups could be considered genetically closer. This allowed easier detection of the influence of long-term sucrose-drinking, an environmental factor, on the incidence of glucose intolerance.

We should also discuss limitations of the present study. First, we should consider the circumstances that rats in the sucrose group had no choice but to drink $300 \mathrm{~g} / \mathrm{l}$ sucrose water when we interpret the present results. This is not the same as the human situation. Moreover, $300 \mathrm{~g} / \mathrm{l}$ sucrose water is three times more concentrated than the soft drinks we usually drink. Body fat gain, which is known to cause glucose intolerance in rats, might be unavoidable under these circumstances. Although we believe our results are meaningful, we should also note that the present study design does not separate the effects of sucrosedrinking from the effects of excess body fat. Hence, any source of excess energy, be it alcohol, milk, starch, protein or fat, might have the same effects. Second, IVGTTs were performed on rats at 8 and 16 weeks of age, although we were able to compare the two groups in the tests. It is well known that incretin respones in IVGTT are different from those in OGTT. We selected IVGTTs on the rats at these weeks of age in order to avoid the risk that the rat digestive organ might be injured by an oral catheter, as we planned long-term examination periods.

The results of most previous studies were consistent with our results regarding fasting plasma insulin in sucrose-drinking rats (i.e. increases in fasting plasma insulin concentrations). In the present study, fasting plasma insulin concentrations in the sucrose group increased to six times those of the control group at 12 weeks of age, although no difference in body weights was observed. Increases in fasting plasma insulin concentrations preceded greater weight gain in the sucrose group. Moreover, fasting plasma insulin concentrations continued to be elevated in the sucrose group after 12 weeks of age. We believe that the elevated insulin concentrations were caused by continuous sucrose-drinking, although we were unable to estimate the daily intake of sucrose water in each rat. When we examined plasma insulin concentrations from OGTTs, we found that these concentrations peaked in the sucrose group $30 \mathrm{~min}$ after loading at 28 weeks of age. At 36 weeks of age, the peak disappeared and hyperinsulinaemia was prolonged, accompanied with the progression of hyperglycaemia. These findings were very similar to those observed in patients with type 2 diabetes.

There are several possible explanations for the apparent hyperglycaemia observed in the sucrose group. First, weight gain plays an important role in the onset of diabetes, because obesity is a remarkably strong risk factor for diabetes in humans (Edelstein et al. 1997). Second, as most previous studies have already demonstrated, sucrose-loading itself leads to glucose intolerance or hyperinsulinaemia in rats. Third, insulin secretion may be genetically weak in our rats. In the control group, the peak plasma insulin concentrations were detected at $60 \mathrm{~min}$, not $30 \mathrm{~min}$, after loading during the IVGTTs in 16-week-old rats and the OGTTs in 28- and 36-weekold rats. Fourth, sucrose-loading might accelerate the loss of islet $\beta$ cells. Koyama et al. (1988) reported accelerated loss of islet $\beta$ cells in sucrose-fed Goto-Kakizaki rats, a spontaneously diabetic model of non-insulin-dependent diabetes. Although we did not examine the volume density of islet $\beta$ cells, we suspect that longer periods of sucrose-loading and progression of hyperglycaemia in the present study could accelerate the loss of islet $\beta$ cells.

In human studies, a positive correlation between obesity and sugar intake was demonstrated in three previous studies (Ludwig et al. 2001; Raben et al. 2002; James et al. 2004). However, a positive relationship between sugar intake and the incidence of type 2 diabetes has not been demonstrated (Meyer et al. 2000; Janket et al. 2003).

The present results were quite different from the results of the human studies. There are several possible reasons for this discrepancy. First, dietary variation before the experimental period can be a confounding factor in human studies. Second, genetic homogeneity did not seem to be confirmed among the comparable groups in human studies. Although crossover study design could solve this problem, most of these studies had short experimental periods, ranging from 2 weeks to 3 months. Third, human epidemiologic studies are often characterized by poor dietary assessment methods (Nelson \& Bringham, 1991). Fourth, accompanying decreases in fat intake might play an important role. Sugar intake and fat intake are generally reciprocally related in humans (Gibney, 1990). In the present study, the intake of the basal non-purified diet was significantly greater in the control group than in the sucrose group (data not shown). This means that fat intake was also significantly greater in the control group. Therefore, glucose intolerance in the sucrose group did not contribute to accompanying increases in fat intake. Fifth, extreme diets in which sucrose accounted for $>60 \%$ of total calories (the highest contribution was $69 \%$; Storlin et al. 1988) are often chosen in animal studies; whereas the highest contribution made by sucrose is approximately $33 \%$ (Reiser et al.1981) in human studies. This difference between human and animal studies may make it difficult to compare results. The percentage of sucrose that was used in the present study is less than the highest percentage of sucrose in human studies.

In conclusion, we found that long-term sucrose-drinking causes increased body weight and glucose intolerance in normal male rats.

\section{References}

Blakely SR, Hallfrisch J, Reiser S \& Prather ES (1981) Long-term effects of moderate fructose feeding on glucose tolerance parameters in rats. $J$ Nutr 111, 307-314.

Chicco A, D'Alessandro ME, Karabatas L, Pastorale C, Basabe JC \& Lombardo YB (2003) Muscle lipid metabolism and insulin secretion are altered in insulin-resistant rats fed a high sucrose diet. $J$ Nutr 133, 127-133.

Edelstein SL, Knowler WC, Brain RP, et al. (1997) Predictors of progression from impaired glucose tolerance to NIDDM: an analysis of six prospective studies. Diabetes 46, 701-710. 
Gibney MJ (1990) Dietary guidelines, a critical appraisal. J Hum Nutr Diet 3, 245-254.

James J, Thomas P, Cavan D \& Kerr D (2004) Preventing childhood obesity by reducing consumption of carbonated drinks: cluster randomised controlled trial. Br Med J 328, 1237.

Janket SJ, Manson JE, Sesso H, Buring JE \& Liu S (2003) A prospective study of sugar intake and risk of type 2 diabetes in women. Diabetes Care 26, 1008-1015.

Koyama M, Wada R, Sakuraba H, Mizukami H \& Yagihashi S (1988) Accelerated loss of islet $\beta$ cells in sucrose-fed Goto-Kakizaki rats, a genetic model of non-insulin-dependent diabetes mellitus. Am $J$ Pathol 153, 537-545.

Kuczmarski RJ, Flegal KM, Campbell SM \& Johnson CL (1994) Increasing prevalence of overweight among US adults: the National Health and Nutrition Examination Surveys, 1960 to 1991. JAMA 272, 205-211.

Levi B \& Werman MJ (1998) Long-term fructose consumption accelerates glycation and several age-related variables in male rats. $J$ Nutr $\mathbf{1 2 8 ,}$ 1442-1449.

Ludwig DS, Peterson KE \& Gortmaker SL (2001) Relation between consumption of sugar-sweetened drinks and childhood obesity: a prospective observational analysis. Lancet 357, 505-508.

Marshall JA, Bessesen DH \& Hamman RF (1997) High saturated fat and low starch and fiber are associated with hyperinsulinaemia in a non-diabetic population: the San Luis Valley Diabetes Study. Diabetologia 40, 430-438.

Meyer KA, Kushi LH, Jacobs Jr DR, Slavin J, Sellers TA \& Folsom AR (2000) Carbohydrates, dietary fiber, and incident type 2 diabetes in older women. Am J Clin Nutr 71, 921-930.
Mokdad AH, Bowman BA, Ford ES, Vinicor F, Marks JS \& Koplan JP (2001) The continuing epidemics of obesity and diabetes in the United States. JAMA 12, 1195-1200.

Nelson M \& Bringham S (1991) Assessment of food consumption and nutrient intake. In Design Concepts in Nutritional Epidemiology, pp. 153-191 [BM Margetts and M Nelson, editors]. New York: Oxford University Press.

Raben A, Vasilaras TH, Møller AC \& Astrup A (2002) Sucrose compared with artificial sweeteners: different effects on ad libitum food intake and body weight after 10wk of supplementation in overweight subjects. Am J Clin Nutr 76, 721-729.

Reiser S, Bohn E, Hallfrisch JG, Michaelis OE IV, Keeny M \& Prather ES (1981) Serum insulin and glucose in hyperinsulinemic subjects fed three different levels of sucrose. Am J Clin Nutr 34, $2348-2358$.

Stark AH, Timar B \& Madar Z (2000) Adaptation of Sprague Dawley rats to long-term feeding of high fat or high fructose diets. Eur J Nutr 39, 229-234.

Storlin LH, Kraegen EW, Jenskins AB \& Chisholm DJ (1988) Effects of sucrose vs starch diets on in vivo insulin action, thermogenesis, and obesity in rats. Am J Clin Nutr 47, 420-427.

Tsunehara CH, Leonetti DL \& Fujimoto WY (1990) Diet of second-generation Japanese-American men with and without non-insulin-dependent diabetes. Am J Clin Nutr 52, 731-738.

Tulp OL, Hansen CT, McKee K \& Michaelis IV OE (1991) Effects of diet and phenotype on adipose cellularity and $5^{\prime}$-deiodinase activity of liver and brown adipose tissue of diabetic SHR/N-cp rats. Comp Biochem Physiol 99A, 457-462. 